\title{
Tratamento de efluentes de refinaria de petróleo em reatores com Aspergillus niger
}

\author{
Treatment of petroleum refinery wastewater by reactors \\ inoculated with Aspergillus niger
}

\author{
Sandra Tédde Santaella \\ Professora-associada do Instituto de Ciências do Mar da Universidade Federal do Ceará (Labomar/UFC)
}

Francisco das Chagas Gomes da Silva Júnior

Engenharia Civil pela UFC. Estagiário da Fundação de Apoio à Pesquisa e à Extensão (Fapex)

\section{Davi de Andrade Cordeiro Gadelha}

Graduando em Engenharia Civil pela UFC. Bolsista do Instituto Nacional de Tecnologia da Informação do Conselho Nacional de Desenvolvimento Científico e Tecnológico (ITI-CNPq) do Fundo Setorial de Petróleo e Gás Natural (CTPetro) da sub-rede Resíduos Líquidos do Nordeste (Reline) da Rede Cooperativa em

Recuperação de Áreas Contaminadas por Atividades Petrolíferas (Recupetro)

\section{Keila Oliveira Costa}

Química pela UFC. Bolsista de DTI-CNPq/CTPetro/Recupetro/Reline

\section{Rodolfo de Aguiar}

Graduando em Engenharia Civil pela UFC. Pesquisador voluntário da Rede Cooperativa em Recuperação de Áreas Contaminadas por Atividades Petrolíferas (Recupetro/Reline)

\section{Isabelle Dias Branco Arthaud}

Bióloga pela UFC. Mestre em Saneamento Ambiental pela UFC. Doutoranda em Biotecnologia da Rede Nordeste de Biotecnologia (Renorbio) na Universidade Estadual do Ceará (UECE)

\section{Renato Carrhá Leitão}

Pesquisador da Embrapa Agroindústria Tropical. Engenheiro Civil. Mestre em Hidráulica e Saneamento. Doutor em Ciências Ambientais pela Universidade de Wageningem, Holanda

\section{Resumo}

Neste trabalho, avaliou-se o efeito do tempo de detenção hidráulica (TDH) no desempenho de três reatores aeróbios inoculados com Aspergillus niger AN400, usados para tratamento de efluentes de refinarias de petróleo. Cada reator foi operado com um tempo de detenção hidráulica diferente: 4 , 8 e 12 horas, durante 152 dias. Eles possuíam leito fixo de espuma de poliuretano e o escoamento era ascendente e contínuo. Determinaram-se: pH, fenóis, demanda química de oxigênio (DQO), amônia, nitrito e nitrato, no afluente e efluentes dos reatores. O TDH de oito horas foi o melhor para remoção de DQO ${ }_{\text {solúvel }}$ e não houve diferença entre os TDHs para remoção de fenóis totais. No período estável não houve remoção de nitrato; no entanto ocorreu remoção de nitrito de aproximadamente 99\%. Além disto, houve produção de amônia devido à amonificação a partir do nitrito presente no meio.

Palavras-chave: água residuária; refinaria de petróleo; tratamento biológico aeróbio; fungos filamentosos; tempo de detenção hidráulica.

\begin{abstract}
This paper evaluated the effect of hydraulic retention time (HRT) on the performance of three upflow aerobic reactors, with polyurethane foam as support material, inoculated with Aspergillus niger AN400, used for the treatment of petroleum refinery wastewater. Each reactor was operated with a different HRT: 4, 8 and 12 hours, during 152 days. The performance was evaluated based on $\mathrm{pH}$; phenols; COD, nitrate and nitrite. The results show that for the COD removal, it is more reasonable to operate the reactor with HRT of eight hours. However, there was no difference among results of phenol removal efficiency of the different HRTs. During steady state condition, nitrite was removed in approximately $99 \%$, but there was no reduction on the nitrate concentration. Ammonia was produced in all reactors, probably due to ammonification of nitrite.
\end{abstract}

Keywords: wastewater; petroleum refinery wastewater; aerobic biological treatment; filamentous fungi; hydraulic retention time. 


\section{Introdução}

Durante o processo de refino do petróleo, são utilizados em média 246 a 340 litros de água por barril de óleo cru (ALVA-ARGÁEZ; KOKOSSIS; SMITH, 2007), gerando uma quantidade de água residuária em torno de 0,4 a 1,6 vezes o volume de óleo processado (FICA-PIRAS, 2000). Durante a transformação do material bruto em produtos tais como gasolina, querosene, lubrificantes, nafta, diesel etc. (DUPUIT et al, 2007) empregam-se para o refino, grande variedade de solventes com diferentes graus de solubilidade para extrair substâncias desejáveis (ALVA-ARGÁEZ; KOKOSSIS; SMITH, 2007). Essas atividades geram efluentes que apresentam grande diversidade de poluentes orgânicos e inorgânicos, incluindo compostos fenólicos, sulfetos, amônia, cianetos, hidrocarbonetos poliaromáticos e alifáticos (ALVA-ARGÁEZ; KOKOSSIS; SMITH, 2007; STEPNOWSKI et al, 2002; STRINGFELLOW; ALVAREZ-COHEN, 1999) que podem ser tóxicos para diversos organismos e potencialmente cancerígenos (ALAJBEG et al, 2000; BARRON et al, 1999; MARIANO, 2001). Muitos dos compostos tóxicos presentes nos despejos das refinarias de petróleo, mesmo quando presentes em concentrações inferiores às letais podem provocar danos à biota seja de ambientes terrestres ou aquáticos. Segundo Alva-Argáez; Kokossis e Smith (2007), essas águas residuárias são geralmente alcalinas e possuem concentrações elevadas de demanda bioquímica de oxigênio (DBO) e de demanda química de oxigênio (DQO), porém, Driessen e Yspeert (1999) classificam as águas residuárias com baixos valores de DQO, como sendo aquelas cujos valores são inferiores a $2.500 \mathrm{mg} / \mathrm{L}$; as médias apresentam DQO entre 3.000 e 7.000 mg/L e as com concentrações elevadas são aquelas com DQO > 7.000 mg/L. Na literatura encontram-se valores de DQO para efluentes de refinarias de petróleo que são caracterizados como "baixos" (Tabela 1).

Geralmente, o tratamento das águas residuárias de refinarias de petróleo é feito em níveis primário e secundário através de processos físicos ou físico-químicos utilizando separadores água-óleo e processos de coagulação-floculação (STEPNOWSKI et al, 2002). O tratamento biológico é feito, principalmente, através de três processos distintos: lagoas de oxidação, lodos ativados e filtros biológicos, dependendo dos custos envolvidos e do tamanho da área disponível para a construção da Estação de Tratamento de Esgotos (ETE) (MARIANO, 2001).

Entre os micro-organismos que podem ser utilizados para o tratamento biológico de efluentes de refinarias de petróleo, os fungos vêm se mostrando hábeis em degradar compostos xenobióticos e outros de grandes cadeias moleculares que, em geral, são de difícil degradação. Os fungos sobrevivem e crescem em meios com concentrações elevadas de compostos recalcitrantes e são capazes de utilizá-los como fonte de energia (EGGEN; MAJCHERCZYK, 1998; ESPOSITO; AZEVEDO, 2004; OLIVEIRA et al, 2006; SANTOS; LINARDI, 2004). Estes micro-organismos produzem enzimas extracelulares oxidativas, capazes de quebrar compostos policíclicos aromáticos de cadeia longa em compostos assimiláveis ao seu metabolismo. Essa atividade é intensificada com a adição de um substrato primário, de fácil assimilação, como a glicose (GRIFFIN, 1994; SAMPAIO et al, 2004A). Entretanto, Santaella et al (2005) sugerem que a glicose seja adicionada somente para a partida dos reatores, visando a acelerar o crescimento inicial dos fungos. Outro mecanismo que melhora a eficiência de remoção de compostos tóxicos pelos fungos, é a sua aplicação nos processos de degradação com células imobilizadas (GODJEVARGOVA et al, 2003).

Segundo Eggen e Majcherczyk (1998), os fungos filamentosos são os mais eficientes na produção de enzimas extracelulares oxidativas (proteases, celulases, ligninases, lactases, entre outras). Dentre eles, o Aspergillus niger tem eficiência comprovada para degradação de compostos recalcitrantes em efluentes de indústria farmacêutica, indústria de azeite de oliva, indústria de castanha de caju, cervejarias, refinarias de petróleo e em água para remoção do pesticida agrícola paration (FÉLIX et al, 2006; FREITAS NETO et al, 2007; GARCIA et al, 2000; HERNÁNDEZ et al, 2006; MIRANDA et al, 1996; SAMPAIO et al, 2004B; SANTAELLA et al, 2002; SANTOS et al, 2006; VASSILEV et al, 1997), trabalhando em uma faixa ótima de pH entre 3,0 e 4,0 (GRIFFIN, 1994).

Várias estações de tratamento de águas residuárias industriais são compostas por sistemas de lodos ativados que são bastante onerosos apesar da boa eficiência de tratamento, ou sistemas anaeróbios, cuja microbiota é sensível às variações ambientais e de cargas orgânica e hidráulica (LEITÃO et al, 2006). Por outro lado, os fungos filamentosos amilolíticos possuem vantagens sobre as bactérias que devem ser consideradas: facilidade de separação da biomassa fúngica, taxa elevada de redução de DQO e uso das proteínas geradas pelos fungos como suplemento alimentar para suínos e aves domésticas. Portanto, é viável o uso de fungos amilolíticos para tratamento de águas residuárias industriais. Entre esses fungos, a capacidade amilolítica do Aspergillus spp. está bem estabelecida (MISHRA; LATA, 2004)

Tabela 1 - Valores de DQO de efluentes de refinarias de petróleo encontrados na literatura

\begin{tabular}{|c|c|c|c|}
\hline Referência & $\mathrm{DQO}_{\text {média }}\left(\mathrm{mg} \mathrm{O}_{2} \cdot \mathrm{L}^{-1}\right)$ & Referência & $\mathrm{DQO}_{\text {média }}\left(\mathrm{mg} \mathrm{O}_{2} \cdot \mathrm{L}^{-1}\right)$ \\
\hline Aruldoss e Viraraghavan (1998) & 1.591 & Coelho et al (2006) & 935 \\
\hline Demrci, Erdogan e Ozcmder (1998) & 800 & Félix et al (2006) & 270 \\
\hline Johnson, Page e Blaha (2000) & 379 & Sousa et al (2006) & 281 \\
\hline Wagner e Nicell (2001) & 306 & Yavuz e Koparal (2006) & 590 \\
\hline
\end{tabular}


Efluentes de refinarias de petróleo possuem compostos nitrogenados tais como: amônia, nitrito e nitrato, em concentrações bastante variáveis, sendo que os teores elevados de amônia são uma das principais preocupações para a operação dos sistemas de tratamento. Por outro lado, estes compostos são essenciais para a nutrição e metabolismo dos fungos, que têm habilidade para utilizar amônia diretamente (anabolismo) ou a partir da redução de nitratos. De forma geral, eles utilizam as fontes inorgânicas de nitrogênio, mas podem também extraí-lo de fontes orgânicas (GRIFFIN, 1994). Com isto, a utilização de fungos para o tratamento de efluentes de refinarias de petróleo pode ser uma alternativa viável.

Os fungos podem adaptar-se às mais variadas concentrações de oxigênio, utilizando desde o oxigênio livre até fontes de oxigênio combinado e, dependendo da concentração de oxigênio no meio em que se encontram, utilizam rotas metabólicas alternativas (desnitrificação e amonificação), além da respiração aeróbia convencional (TAKAYA, 2002). Essa capacidade de adaptação confere aos fungos inúmeras vantagens sobre as bactérias quando da utilização em sistemas de tratamento de águas residuárias.

O objetivo deste trabalho foi comparar o desempenho de reatores biológicos inoculados com o fungo Aspergillus niger AN400, em escala de laboratório, sob diferentes tempos de detenção hidráulica (TDHs), para remover matéria orgânica, fenóis totais e compostos nitrogenados de águas residuárias de refinarias de petróleo após o tratamento primário.

\section{Material e métodos}

Neste trabalho optou-se por Aspergillus niger pela comprovada eficiência na remoção de compostos recalcitrantes e nitrogenados e, segundo Esposito e Azevedo (2004), por possuir melanina que o protege de estresses ambientais tais como condições hiperosmóticas, temperaturas extremas, antagonismo com outros micro-organismos, limitações de nutrientes, modificações abruptas no pH e radiações ionizantes. Utilizaram-se reatores de leito fixo e biofilme aderido por oferecerem grande eficiência e estabilidade, principalmente quando se necessita de alta taxa de degradação (JOU; HUANG, 2002).

A água residuária utilizada foi coletada semanalmente ao final da cadeia de processamento da refinaria de petróleo da Petrobras localizada em Fortaleza no Ceará nas Lubrificantes e Derivados de Petróleo do Nordeste (Lubnor), no poço de sucção localizado após o separador água-óleo e imediatamente antes do tratamento secundário. Foram montados três reatores cilíndricos, aeróbios, de leito fixo submerso e escoamento contínuo ascendente, confeccionados em acrílico, possuindo $60 \mathrm{~cm}$ de altura, $10 \mathrm{~cm}$ de diâmetro e volume útil de 2,5 L. Cada reator possuía dois orifícios na base, sendo um para entrada do afluente e outro para aeração, além de um orifício na parte superior para a saída do efluente. Como meio suporte foi empregada espuma de poliuretano, cortada em cubos de aproximadamente $2 \mathrm{~cm}$ de aresta, em quantidade suficiente para preencher $80 \%$ da altura do reator. Os reatores foram operados simultaneamente durante 152 dias, sendo que foram necessários 69 dias para a estabilização (partida) e 83 em fase estável; cada um com um tempo de detenção hidráulica diferente ( 4 , 8 e 12 horas). O esquema da instalação experimental é apresentado na Figura 1.

Os reatores foram inoculados misturando-se $2 \times 10^{6}$ esporos $/ \mathrm{mL}$, de Aspergillus niger AN400, com meio de cultura caldo Sabouraud (Difco). O preenchimento dos reatores foi realizado em camadas, alternando-se a solução contendo o meio de cultura, esporos de fungos, glicose e meio suporte. Após o preenchimento, os reatores permaneceram sem aeração e escoamento, durante 24 horas, para o desenvolvimento do micélio. Posteriormente os reatores passaram a ser aerados, durante aproximadamente uma semana, para facilitar a formação do biofilme. Depois de ocorrer a formação do biofilme e o consumo do meio de cultura, iniciou-se a alimentação contínua dos reatores com a água residuária e adição de glicose $\left(0,5\right.$ g.L $\left.\mathrm{L}^{-1}\right)$ que, segundo Griffin (1994), reduz a fase lag de crescimento dos fungos. Neste período os parâmetros de interesse passaram a ser monitorados. Concluída a primeira semana de escoamento contínuo, o suplemento de fonte primária de carbono (glicose) foi retirado, conforme sugerido por Arthaud (2005).

Após a coleta, a água residuária era armazenada em um reservatório, continuamente homogeneizada e acidificada com $\mathrm{HCl}$ até $\mathrm{pH}$ 3,0 para evitar crescimento bacteriano e fornecer $\mathrm{pH}$ ideal para o metabolismo do Aspergillus niger AN400. Bombas de diafragma recalcavam o afluente para os reatores. A aeração era feita através de minicompressores de ar, acoplados às bases dos reatores.

As variáveis monitoradas durante a pesquisa, tanto do afluente quanto do efluente dos reatores foram: $\mathrm{pH}$, nitrato $\left(\mathrm{N}-\mathrm{NO}_{3}{ }^{-}\right)$, nitrito $\left(\mathrm{N}-\mathrm{NO}_{2}^{-}\right)$, amônia $\left(\mathrm{N}-\mathrm{NH}_{3}\right)$, fenóis totais e DQO. Todos os parâmetros foram determinados segundo os métodos descritos em APHA (2005). Os resultados foram submetidos à análise estatística que constou de duas avaliações: foi iniciada com a aplicação do teste F, objetivando estimar a significância das variações de dois períodos e verificar qual apresentava maior estabilidade. Posteriormente, realizou-se a aplicação do teste $t$ de Student e o método do valor de p (TRIOLA, 1998), para avaliar diferenças

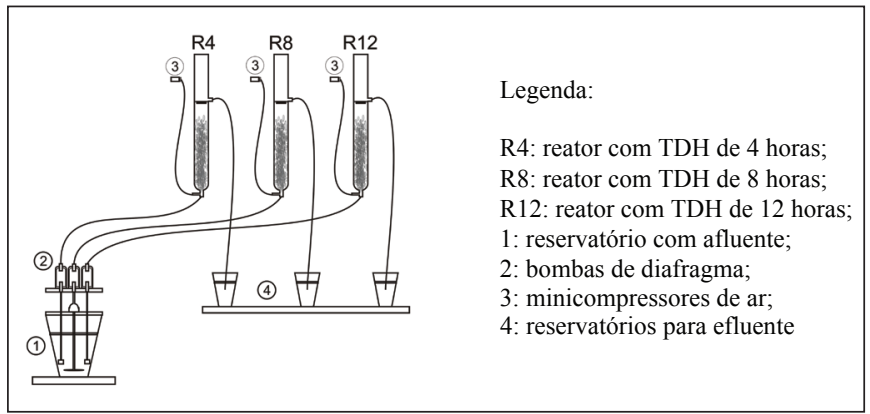

Figura 1 - Esquema dos reatores de escoamento contínuo 
significativas entre as médias obtidas para cada reator. Neste trabalho utilizou-se $\mathrm{p} \leq 0,05$.

\section{Resultados e discussão}

Os resultados obtidos estão apresentados, em forma de tabelas e gráficos, com os respectivos valores de mínimo, máximo, média, desvio padrão (dp) e intervalo de confiança (IC). Aplicando-se análise estatística, os resultados mostraram que a partir do $69^{\circ}$ dia de operação, os reatores estavam em estado de estabilidade aparente.

\section{$\mathrm{pH}$}

Os valores de $\mathrm{pH}$ afluente e efluente, durante o período de partida e período estável dos reatores R4, R8 e R12 estão na Tabela 2.

Em tratamento biológico, o $\mathrm{pH}$ da água residuária a ser tratada deve ser controlado, para que a atividade dos micro-organismos mantenha-se em um nível ótimo. Segundo Griffin (1994), o pH ótimo para o desenvolvimento de vários fungos encontra-se na faixa entre 4,0 e 6,0, porém, a maioria dos fungos filamentosos tolera variações de $\mathrm{pH}$ entre 2,0 e 9,0. Os valores de $\mathrm{pH}$ mais adequados para a atividade de Aspergillus niger são aqueles próximos de 4,0 (DACERA; BABEL, 2008; KYRIACOU et al, 2005; MISHRA; LATA, 2004). Neste trabalho, o pH foi mantido entre 3,0 e 4,0 para evitar a proliferação de bactérias nos reatores.

Os valores de pH de saída dos reatores R4, R8 e R12 foram próximos aos valores de entrada, em torno de 3,5 $\pm 0,4$, não havendo diferenças significativas, mantendo-se propícios ao desenvolvimento do Aspergillus niger. Porém, Mishra e Lata (2004) que estudaram a influência do pH na remoção de DQO de água residuária de indústria alimentícia, tratada com Aspergillus niger e Aspergillus foetidus, concluíram que houve maior remoção de DQO em pH 6,0, embora houvesse maior atividade amilolítica em pH 4,0.
DQO

As concentrações de $\mathrm{DQO}_{\text {Total }}$ afluente e efluente dos reatores estão apresentadas na Tabela 3. Os valores de DQO afluente são compatíveis com os de outros trabalhos realizados com efluente da mesma refinaria (FÉLIX et al, 2006; SOUSA et al, 2006) e de outras refinarias (DUPUIT et al, 2007), porém inferiores aos mencionados na Tabela 1; variando em função da origem do petróleo e do processo de refino.

Durante o período estável foram obtidas porcentagens médias de remoção de DQO de $39 \pm 8 \% ; 40 \pm 10 \%$ e $43 \pm 11 \%$, respectivamente para R4, R8 e R12, não havendo evidência significativa de diferença entre as remoções dos reatores $\mathrm{R} 4, \mathrm{R} 8$ e R12. Isto é uma indicação de que tempos de detenção de quatro horas podem ser utilizados com pouco comprometimento da eficiência de remoção de $\mathrm{DQO}_{\text {Total }}$.

Durante a primeira semana de operação, os reatores R4, R8 e R12 apresentaram melhores porcentagens de remoção de DQO com valores de 71, 67 e 73\%, respectivamente, isto ocorreu pela adição de 0,5 g.. - $^{-1}$ de glicose que, segundo Griffin (1994); Esposito e Azevedo (2004) e Félix et al (2006), favorece o metabolismo fúngico aumentando a eficiência de remoção de matéria orgânica.

A determinação de $\mathrm{DQO}_{\text {solúvel }}$ é importante quando se deseja saber se compostos orgânicos dissolvidos estão sendo removidos pelo sistema de tratamento. A determinação de $\mathrm{DQO}_{\text {Solúvel }}$ foi realizada a partir do $69^{\circ}$ dia de operação dos reatores, obtendo-se remoção média de $30 \pm 9 \%, 44 \pm 12 \%$ e $49 \pm 10 \%$, para R4, R8 e R12, respectivamente. A eficiência de remoção pode ser considerada boa se for observado que a $\mathrm{DQO}_{\text {Solúvel }}$ afluente era muito baixa (Tabela 4) dificultando os processos de degradação da matéria orgânica pelos microorganismos. Baixas concentrações de DQO no afluente diminuem a concentração de substrato dentro dos reatores biológicos, gerando problemas relacionados com a transferência de massa (KATO et al, 1997). Se a alimentação do reator com baixas concentrações durar

Tabela 2 - Valores de pH afluente e efluente dos reatores

\begin{tabular}{|c|c|c|c|c|c|c|c|c|c|c|}
\hline \multirow{2}{*}{$\mathrm{pH}$} & \multicolumn{2}{|c|}{ Mínimo } & \multicolumn{2}{|c|}{ Máximo } & \multicolumn{2}{|c|}{ Média } & \multicolumn{2}{|c|}{$d p$} & \multicolumn{2}{|c|}{ IC } \\
\hline & $\mathrm{P}$ & $E$ & $\mathrm{P}$ & E & $P$ & $E$ & $P$ & $E$ & $P$ & $E$ \\
\hline Afluente & 2,59 & 2,94 & 4,04 & 3,88 & 3,31 & 3,40 & 0,41 & 0,24 & 0,23 & 0,11 \\
\hline $\mathrm{R} 4$ & 2,60 & 2,98 & 3,92 & 3,89 & 3,32 & 3,41 & 0,39 & 0,24 & 0,21 & 0,11 \\
\hline R8 & 2,58 & 2,99 & 3,96 & 3,86 & 3,33 & 3,38 & 0,41 & 0,23 & 0,22 & 0,11 \\
\hline $\mathrm{R} 12$ & 2,58 & 2,99 & 3,87 & 3,83 & 3,31 & 3,40 & 0,37 & 0,23 & 0,20 & 0,11 \\
\hline
\end{tabular}

P: partida do reator (13 determinações); E: período estável (18 determinações).

Tabela 3 - Concentrações de $\mathrm{DQO} \mathrm{T}_{\text {Total }}$ afluente e efluente dos reatores

\begin{tabular}{|c|c|c|c|c|c|c|c|c|c|c|}
\hline \multirow{2}{*}{$\mathrm{DQO}_{\text {Total }}\left(\mathrm{mg} \mathrm{O}_{2} \cdot \mathrm{L}^{-1}\right)$} & \multicolumn{2}{|c|}{ Mínimo } & \multicolumn{2}{|c|}{ Máximo } & \multicolumn{2}{|c|}{ Média } & \multicolumn{2}{|c|}{$d p$} & \multicolumn{2}{|c|}{ IC } \\
\hline & 1 & $E$ & I & $E$ & 1 & $E$ & 1 & $E$ & I & $E$ \\
\hline Afluente & 26,3 & 23,5 & 395,9 & 204,7 & 153,0 & 84,2 & 125,4 & 51,4 & 77,7 & 23,8 \\
\hline R4 & 26,6 & 16,0 & 166,4 & 107,4 & 89,4 & 46,7 & 77,0 & 25,6 & 47,7 & 11,8 \\
\hline R8 & 14,7 & 13,5 & 99,4 & 168 & 56,8 & 50,8 & 27,1 & 41,6 & 16,8 & 19,2 \\
\hline $\mathrm{R} 12$ & 14,1 & 18,5 & 64,5 & 71,3 & 48,7 & 41,3 & 28,8 & 19,1 & 17,8 & 8,8 \\
\hline
\end{tabular}

I: período instável (9 determinações); E: período estável (18 determinações). 
um período elevado, a concentração de biomassa viável tenderá a diminuir, causando redução nas taxas de conversão (MORDOCCO; KUEK; JENKINS, 1999).

Não foi verificada diferença significativa na eficiência de remoção entre R12 e R8 e entre R8 e R4, mas houve diferença de eficiência de remoção entre R12 e R4, mostrando a tendência de aumento de eficiência com o aumento do TDH (Figura 2). Sendo assim, baseando-se em aspectos econômicos, o TDH de oito horas é o mais indicado porque não houve diferença significativa entre as eficiências de remoção de $\mathrm{DQO}_{\text {Solúvel }}$ entre os reatores R8 e R12.

\section{Fenóis}

Geralmente, águas residuárias de refinarias de petróleo contêm concentrações de fenóis muito baixas e bastante variáveis; 193 mg.L-1 (YAVUZ; KOPARAL, 2006), 98 a 128 mg..-1 (COELHO et al, 2006), 8 mg.L $L^{-1}$ (DEMRCI; ERDOGAN; OZCMDER, 1998), 7 mg.L-1

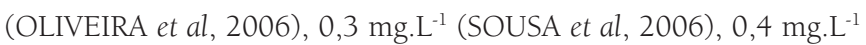
(FÉLIX et al, 2006) e, como explicado por Kato et al (1997), quanto menor a concentração de substrato nas águas residuárias, mais difícil se torna sua remoção por tratamento biológico.

O fungo Aspergillus niger é reconhecido por sua capacidade de remover compostos fenólicos de águas residuárias (KOTSOU et al, 2004; RAO; VIRARAGHAVAN, 2002; RODRIGUES et al, 2005; SANTAELLA et al, 2005), inclusive daquelas com baixas concentrações de fenóis (FÉLIX et al, 2006; RAO; VIRARAGHAVAN, 2002). Até o oitavo dia de operação, durante a partida dos reatores e enquanto a glicose foi adicionada como fonte primária de carbono, verificou-se remoção média

Tabela 4 - Concentrações de $\mathrm{DQO}_{\text {Solúvel }}$ afluente e efluente dos reatores

\begin{tabular}{lccccc}
$\mathrm{DQO}_{\text {Solúvel }}\left(\mathrm{mg} \mathrm{O}_{2} \cdot \mathrm{L}^{-1}\right)$ & Mínimo & Máximo & Média & $\mathrm{dp}$ & $\mathrm{IC}$ \\
\hline Afluente & 25,3 & 114,7 & 53,6 & 31,7 & 14,7 \\
\hline R4 & 13,7 & 84,7 & 36,5 & 23,2 & 10,7 \\
R8 & 6,0 & 101,3 & 32,6 & 30,6 & 14,1 \\
R12 & 6,0 & 71,3 & 28,1 & 22,4 & 10,4 \\
\hline
\end{tabular}

número de determinações: 18.

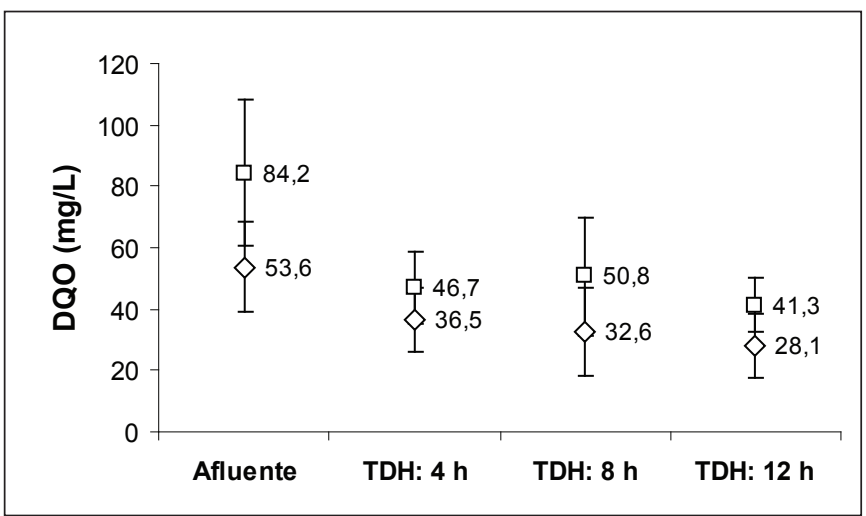

Figura 2 - Comparação entre os valores médios de DQO total ( $\square$ ) e solúvel $(\diamond)$ durante o período estável e respectivos intervalos de confiança de 28, 83 e 88\%, para R4, R8 e R12, respectivamente. Contudo nos dias posteriores, sem a adição de glicose, os valores médios de remoção mudaram para $40 \pm 21 \%$, $46 \pm 18 \%$ e $49 \pm 20 \%$, para R4, R8 e R12, respectivamente, indicando que o reator $\mathrm{R} 4$ ainda estava em fase de adaptação quando a glicose foi retirada e que esta deve ser necessária como fonte primária de carbono durante a remoção destes compostos. Embora essas eficiências de remoção não sejam elevadas, quando são consideradas as baixas concentrações afluentes (Tabela 5), observa-se a capacidade do fungo em remover fenóis. Na Figura 3, estão apresentados os valores médios das concentrações de fenóis durante o período de operação dos reatores.

Kotsou et al (2004) conseguiram remoção de 41\% em reatores de fluxo contínuo com TDH de dois dias e concentração inicial de fenóis totais de $320 \mathrm{mg} / \mathrm{L}$, muito superior à empregada neste trabalho, o que comprova que o Aspergillus niger pode ser utilizado para tratar águas residuárias com pequenas concentrações de fenóis.

Não há diferença significativa entre as remoções de fenóis nos três reatores e, portanto, aumentar o TDH até 12 horas não é uma solução viável para obter maiores remoções de fenóis totais. Sendo assim, o reator com TDH de quatro horas apresentou resultado satisfatório com remoção média de 40\%. Félix et al (2006), trabalhando com efluente da mesma refinaria e reator semelhante ao desta pesquisa, com pH do afluente igual a três e com TDH de oito horas, obtiveram remoção de $75 \%$ de fenóis quando utilizaram glicose como fonte primária de carbono e de 58\% sem adição de glicose, porém, a concentração inicial de fenóis era $0,45 \mathrm{mg} \cdot \mathrm{L}^{-1}$, bastante superior à desta pesquisa $\left(0,28 \mathrm{mg} . \mathrm{L}^{-1}\right)$; portanto estes dois fatores devem ter facilitado a remoção.

Tabela 5 - Concentrações de fenóis afluente e efluente dos reatores

\begin{tabular}{lcccccccccc} 
Fenóis & \multicolumn{2}{c}{ Mínimo } & \multicolumn{2}{c}{ Máximo } & \multicolumn{2}{c}{ Média } & \multicolumn{2}{c}{ dp } & \multicolumn{2}{c}{ IC } \\
(mg.L-1) & I & E & I & E & I & E & I & E & I & E \\
Afluente & 0,08 & 0,05 & 0,65 & 0,75 & 0,23 & 0,28 & 0,20 & 0,24 & 0,12 & 0,13 \\
R4 & 0,07 & 0,04 & 0,56 & 0,30 & 0,21 & 0,11 & 0,16 & 0,07 & 0,10 & 0,04 \\
R8 & 0,03 & 0,02 & 0,52 & 0,32 & 0,17 & 0,11 & 0,15 & 0,10 & 0,09 & 0,06 \\
R12 & 0,02 & 0,02 & 0,58 & 0,24 & 0,14 & 0,09 & 0,16 & 0,06 & 0,10 & 0,03
\end{tabular}

I: período instável (10 determinações); E: período estável (12 determinações).

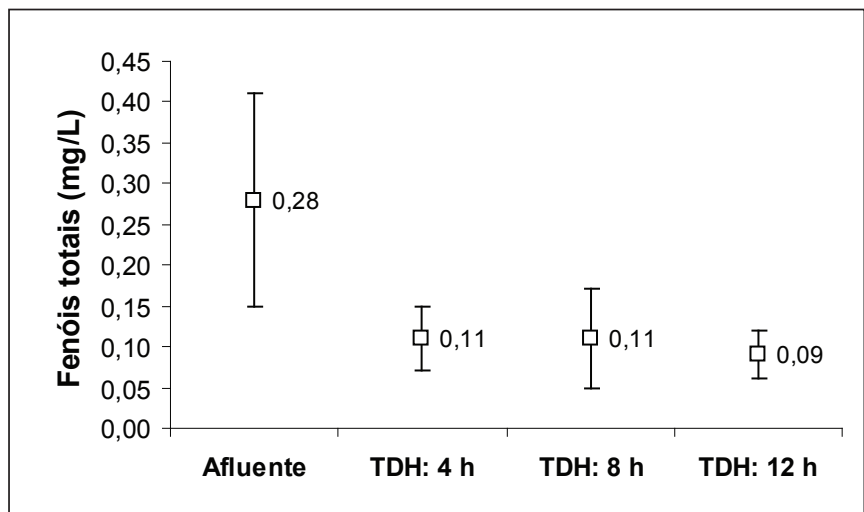

Figura 3 - Comparação entre os valores médios de fenóis durante 0 período estável e respectivos intervalos de confiança dos reatores 


\section{Compostos nitrogenados}

As concentrações de amônia, nitrito e nitrato normalmente encontradas em efluentes de refinarias de petróleo são bastante variáveis. Freitas Neto et al (2007) obtiveram valores médios iguais a $0,73 \pm 0,44 \mathrm{mg} \mathrm{N}-\mathrm{NO}_{3} \cdot \mathrm{L}^{-1} ; 0,4 \pm 0,27 \mathrm{mg} \mathrm{N}-\mathrm{NO}_{2} \cdot \mathrm{L}^{-1}$ e 13,80 \pm $6,7 \mathrm{mg} \mathrm{N}-\mathrm{NH}_{3} \cdot \mathrm{L}^{-1}$. Nesta pesquisa os valores de compostos nitrogenados encontrados foram de 3,43 $\pm 2,04 \mathrm{mg} \mathrm{N}-\mathrm{NO}_{3} \cdot \mathrm{L}^{-1} ; 6,52 \pm$ $3,54 \mathrm{mg} \mathrm{N}-\mathrm{NO}_{2} \cdot \mathrm{L}^{-1}$ e de $7,11 \pm 5,33 \mathrm{mg} \mathrm{N}-\mathrm{NH}_{3} \cdot \mathrm{L}^{-1}$. A concentração de amônia no afluente aos reatores está apresentada na Tabela 6 , bem como os valores nos efluentes dos reatores.

A amônia é bastante utilizada como nutriente pelos fungos, porém, quando o meio é básico, ela se torna tóxica para estes microorganismos. O Aspergillus niger necessita de fonte de nitrogênio para a produção de ácido cítrico (HAQ et al, 2005) e, se houver $\mathrm{NH}_{4} \mathrm{NO}_{3}$, ele utilizará preferencialmente o íon amônio em relação ao nitrato (GRIFFIN, 1994). Contudo, pode ocorrer inibição na utilização de nitrato de amônio se o nitrito intracelular for convertido a nitrato (HAQ et al, 2005). De acordo com Esposito e Azevedo (2004), os fungos podem utilizar amônia $\left(\mathrm{NH}_{3}\right)$ por difusão simples através da membrana celular, mas íons amônio $\left(\mathrm{NH}_{4}^{+}\right)$não atravessam a parede celular. Porém, Roukas e Harvey (1988) explicaram que no interior da célula, nitrato é convertido a nitrito e este ao íon amônio que então é utilizado pelo fungo. Para que isto ocorra o pH ótimo deve estar entre 4 e 6 e o íon amônio não será metabolizado intracelularmente se o pH for inferior a 4 (GRIFFIN, 1994). Freitas Neto et al (2007) trataram o mesmo efluente utilizado nesta pesquisa, em reatores biológicos

Tabela 6 - Concentrações de amônia afluente e efluente dos reatores

\begin{tabular}{lcccccccccc}
$\begin{array}{l}\text { Amônia } \\
\text { (mg N- }\end{array}$ & \multicolumn{2}{c}{ Mínimo } & \multicolumn{2}{c}{ Máximo } & \multicolumn{2}{c}{ Média } & \multicolumn{2}{c}{ dp } & \multicolumn{2}{c}{ IC } \\
NH $_{3} /$ L) & I & E & I & E & I & E & I & E & I & E \\
\hline Afluente & 3,64 & 0,28 & 6,58 & 15,42 & 4,38 & 7,11 & 1,47 & 5,33 & 1,44 & 2,28 \\
R4 & 3,78 & 0,84 & 6,72 & 18,06 & 4,83 & 8,62 & 1,33 & 5,60 & 1,30 & 2,39 \\
R8 & 3,92 & 0,98 & 6,44 & 17,39 & 4,76 & 7,96 & 1,16 & 5,40 & 1,14 & 2,31 \\
R12 & 3,78 & 1,12 & 6,30 & 17,78 & 4,62 & 8,28 & 1,16 & 5,46 & 1,14 & 2,34 \\
\hline
\end{tabular}

I: período instável (quatro determinações); E: período estável (21 determinações).

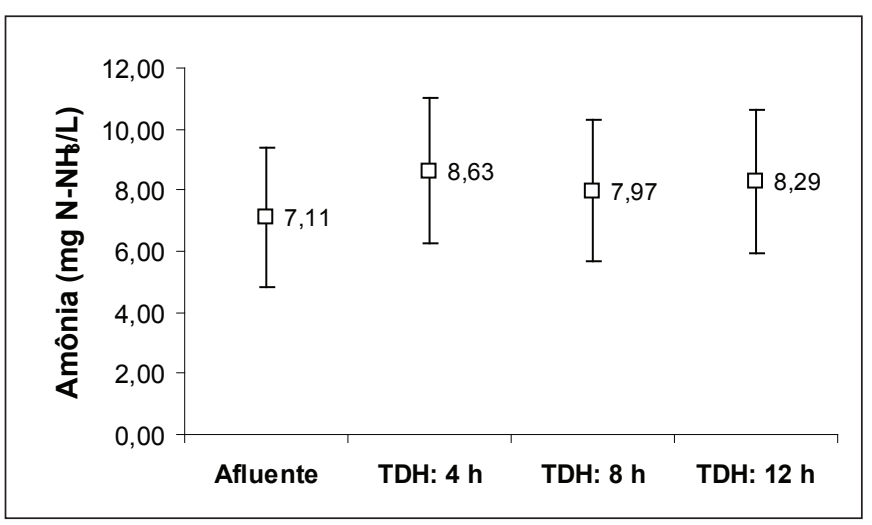

Figura 4 - Comparação entre os valores médios de amônia durante 0 período estável e respectivos intervalos de confiança dos reatores inoculados com Aspergillus niger AN400, com TDH de oito horas e obtiveram produção média de 43\% de amônia. Os autores atribuíram este resultado à presença de bactérias detectadas em análise microbiológica. Entretanto, o pH do meio era inferior a 4, o que impede que o íon amônio seja assimilado pelo fungo (GRIFFIN, 1994).

Verificou-se produção de amônia nos reatores R4, R8 e R12, obtendo-se valores médios de $24 \pm 8 \%, 20 \pm 7 \%$ e $21 \pm 8 \%$, respectivamente. As concentrações médias de amônia no afluente e nos efluentes dos três reatores, durante os 89 dias de operação na fase estável, estão apresentadas na Figura 4.

Observou-se que, mesmo com a diferença no TDH dos três reatores, a produção de amônia entre eles não apresentou evidência de diferença. Se nitrito e amônia estivessem presentes e o pH estivesse entre 4 e 6 , haveria predileção pela amônia (HWANG et al, 2004). Contudo, o pH era 3,4 e, portanto, a amônia não foi usada pelo fungo. Além do baixo pH do meio, que impede a assimilação do íon amônio e favorece a de nitrito, a temperatura ambiente, em torno de $28{ }^{\circ} \mathrm{C}$ também contribuiu para o não-consumo de amônia pois, de acordo com Hwang et al (2004) temperaturas próximas de $22{ }^{\circ} \mathrm{C}$ são as melhores para utilização de compostos nitrogenados por Aspergillus niger e a taxa de consumo de compostos nitrogenados diminui conforme a temperatura aumenta.

Segundo Griffin (1994), nitrito é tóxico para alguns fungos, porém pode ser utilizado por fungos que têm habilidade para consumo de nitrato. O Aspergillus niger é um fungo com habilidade para degradar resíduos nitrogenados, retirando amônia e nitrito do meio. Como o nitrito é um composto intermediário e bastante instável, geralmente as concentrações encontradas nos efluentes tratados são muito pequenas ou abaixo do limite de detecção do método (mínimo de $0,005 \mathrm{mg} \mathrm{N}-\mathrm{NO}_{2} / \mathrm{L}$ ). Neste trabalho, a concentração de nitrito afluente aos reatores era elevada e mesmo com excelente eficiência de remoção, este íon ainda foi detectado no efluente dos reatores (Tabela 7). Houve remoção de nitrito em todos os reatores (Figura 5), obtendo-se 99,7 \pm 0,3\%, 99,8 \pm 0,1\% e 99,7 \pm 0,3\% para R4, R8 e R12, respectivamente. Os valores médios de remoção não apresentaram diferenças significativas com o aumento no TDH, indicando que com TDH de quatro horas ocorre remoção satisfatória de nitrito.

Na Tabela 8 estão apresentados os resultados obtidos das determinações de nitrato no afluente e efluente dos reatores.

Durante o período estável (Figura 6) os três reatores apresentaram aumento insignificante nas concentrações de nitrato efluentes em relação ao afluente e não houve diferença entre os TDHs ( $p \leq 0,05)$.

Os fungos possuem sistemas desnitrificantes nos quais a respiração na mitocôndria está acoplada com a síntese de trifosfato de adenosina (ATP), como na respiração bacteriana. Desta forma, em concentrações muito baixas de oxigênio livre estes organismos usam duas rotas metabólicas diferentes: a desnitrificação na qual transformam $\mathrm{NO}_{3}^{-}$e $\mathrm{NO}_{2}^{-}$em $\mathrm{N}_{2} \mathrm{O}$ e $\mathrm{N}_{2}$ e a amonificação na qual $\mathrm{NO}_{3}^{-}$é reduzido a $\mathrm{NH}_{4}^{+}$. Durante a desnitrificação, óxido nítrico (NO) é 
Tabela 7 - Concentrações de nitrito afluente e efluente dos reatores

\begin{tabular}{|c|c|c|c|c|c|c|c|c|c|c|}
\hline \multirow{2}{*}{ Nitrito (mg N-NO $/ 2$ L) } & \multicolumn{2}{|c|}{ Mínimo } & \multicolumn{2}{|c|}{ Máximo } & \multicolumn{2}{|c|}{ Média } & \multicolumn{2}{|c|}{$d p$} & \multicolumn{2}{|c|}{ IC } \\
\hline & 1 & $E$ & I & $E$ & 1 & $E$ & I & $E$ & I & $E$ \\
\hline Afluente & 1,473 & 12,387 & 11,309 & 16,375 & 6,524 & 13,560 & 3,541 & 1,485 & 2,023 & 1,189 \\
\hline $\mathrm{R} 4$ & 0,001 & 0,001 & 0,115 & 0,123 & 0,023 & 0,050 & 0,032 & 0,057 & 0,019 & 0,046 \\
\hline R8 & 0,002 & 0,001 & 0,158 & 0,052 & 0,022 & 0,028 & 0,045 & 0,018 & 0,027 & 0,014 \\
\hline R12 & 0,001 & 0,006 & 0,068 & 0,140 & 0,012 & 0,042 & 0,020 & 0,055 & 0,012 & 0,044 \\
\hline
\end{tabular}

I: período instável (11 determinações); E: período estável (seis determinações).

reduzido a $\mathrm{N}_{2} \mathrm{O}$ (oxído nitroso) e é catalizada pelo citocromo P4502 (P450nor), que é mais eficiente que o citocromo NO redutase das bactérias. Durante a amonificação, $\mathrm{NO}_{3}$-é reduzido a $\mathrm{NO}_{2}$ - e o mesmo a $\mathrm{NH}_{4}{ }^{+}$pela ação das enzimas $\mathrm{NO}_{3}$ redutase (Nar) e $\mathrm{NO}_{2}$ redutase (Nir) (TAKAYA et al, 1999; TAKAYA, 2002).

Do que foi exposto, duas hipóteses são levantadas para explicar o comportamento dos compostos nitrogenados nos reatores; a primeira é que a presença de oxigênio dissolvido inibiu o processo de desnitrificação via nitrato e a segunda é que ocorreu amonificação a partir do nitrito presente no meio, influenciada mais pelo pH do que pela aeração.

\section{Considerações finais}

Mais estudos precisam ser realizados para se encontrar a concentração ideal de fonte primária de carbono que favoreça a remoção de DQO e fenóis totais, sem provocar crescimento excessivo do fungo. Além disso, outras pesquisas devem ser desenvolvidas para que se conheça mais detalhadamente a influência e as inter-relações das concentrações de oxigênio e pH do meio, através de técnicas de respirometria. Finalmente, outros fungos poderiam ser estudados para degradação dos compostos recalcitrantes, tais como aqueles presentes na própria água residuária.

\section{Conclusões}

Os três reatores só apresentaram estabilidade após 69 dias de operação e o Aspergillus niger usado nesta pesquisa foi capaz de biorremediar águas residuárias com baixas concentrações de DQO e fenóis totais, porém há indícios de que o uso de fonte primária de carbono aumentará as eficiências de remoção. As concentrações de fenóis totais obtidas nos efluentes dos reatores obedeceram às exigências legais de concentração máxima de 0,5 mg/L de fenóis para lançamento de efluentes em corpos d'água, o que está disposto na resolução Conama no 397 (BRASIL, 2008).

Comparando-se os TDHs concluiu-se que o melhor TDH para remoção de $\mathrm{DQO}_{\text {Solúvel }}$ foi o de oito horas e que não há diferença significativa entre os três TDHs, para remoção de fenóis totais.

Os TDHs também não influenciaram o comportamento dos compostos nitrogenados e há indicações de que a concentração de oxigênio e o pH do meio influenciam muito mais a variação dos compostos nitrogenados do que o TDH.

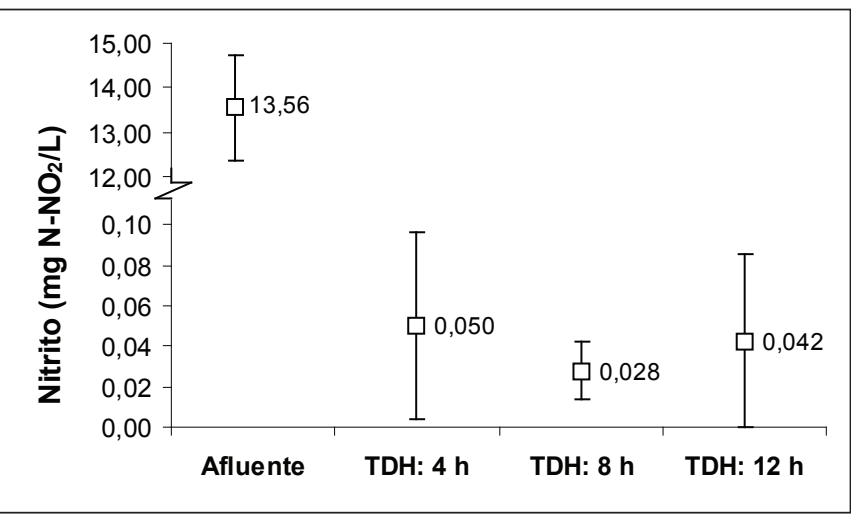

Figura 5 - Comparação entre os valores médios de nitrito durante 0 período estável e respectivos intervalos de confiança dos reatores

Tabela 8 - Concentrações de nitrato afluente e efluente dos reatores

\begin{tabular}{lccccccccccc}
$\begin{array}{l}\text { Nitrato } \\
\text { (mg N- }\end{array}$ & \multicolumn{2}{c}{ Mínimo } & \multicolumn{3}{c}{ Máximo } & \multicolumn{3}{c}{ Média } & \multicolumn{2}{c}{ dp } & \multicolumn{2}{c}{ IC } \\
NO $_{3}$ /L) & I & E & I & E & I & E & I & E & I & E \\
Afluente & 0,36 & 0,01 & 6,42 & 5,28 & 3,43 & 1,46 & 2,04 & 2,01 & 1,15 & 1,49 \\
\hline R4 & 0,32 & 0,02 & 6,64 & 8,03 & 3,33 & 2,30 & 2,01 & 3,10 & 1,14 & 2,30 \\
R8 & 0,27 & 0,02 & 7,18 & 7,52 & 3,91 & 2,14 & 2,00 & 2,83 & 1,13 & 2,10 \\
R12 & 0,27 & 0,01 & 7,32 & 8,72 & 4,17 & 2,08 & 1,85 & 3,11 & 1,05 & 2,31 \\
\hline
\end{tabular}

I: período instável (12 determinações); E: período estável (sete determinações).

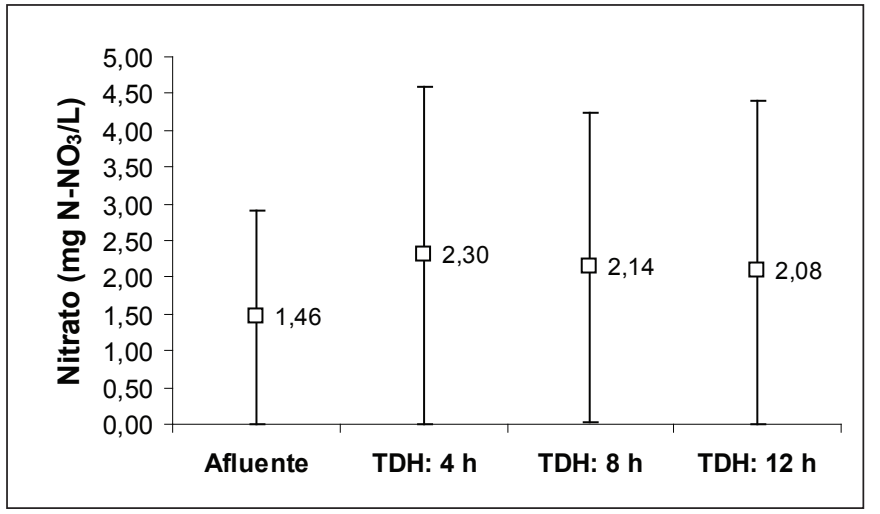

Figura 6 - Comparação entre os valores médios de nitrato durante 0 período estável e respectivos intervalos de confiança dos reatores

\section{Agradecimentos}

Os autores agradecem à Financiadora de Estudos e Projetos (Finep), ao Conselho Nacional de Desenvolvimento Científico e Tecnológico (CNPq) e à Petróleo Brasileiro S/A (Petrobras) pelo 
financiamento da pesquisa, através do edital do Fundo Setorial de Petróleo e Gás Natural (CTPetro) do CNPq-Finep 03/2001; à Lubrificantes e Derivados do Petróleo do Nordeste (LubnorPetrobras) do Ceará pelo apoio; ao $\mathrm{CNPq}$ pela concessão de bolsa de Desenvolvimento Tecnológico Industrial (DTI) e Iniciação Tecnológica Industrial (ITI), para a realização da pesquisa, e à Fundação de Apoio à Pesquisa e à Extensão (Fapex), pela concessão de estágio para a realização da pesquisa.

\section{Referências}

ALAJBEG, I. et al. Comparison of the composition of some petroleum samples which may be applied for skin and mucous membrane treatment. Journal of Pharmaceutical and Biomedical Analysis, v. 22, n. 1, p. $75-84,2000$.

ALVA-ARGÁEZ, A.; KOKOSSIS, A.C.; SMITH, R. The design of waterusing systems in petroleum refining using a water-pinch decomposition. Chemical Engineering Journal, v. 128, n. 1, p. 33-46, 2007.

APHA/AWWA/WEF. Standard methods for the examination of water and wastewater. 21st edition. Washington, D.C. American Health Association, 2005.

ARTHAUD, I.D.B. Redução de toxicidade do efluente de uma refinaria de petróleo, empregando reatores biológicos aeróbios, de leito fixo e fluxo contínuo ascendente, inoculados com Aspergillus níger. Tese (Mestrado em Saneamento) - UFC, Fortaleza, 2005

ARULDOSS, J.A.; VIRARAGHAVAN, T. Toxicity testing of refinery wastewater using Microtox. Bulletin of Environmental Contamination and Toxicology, v. 60, n. 3, p. 456-463, 1998.

BARRON, M.G. et al. Are aromatic hydrocarbons the primary determinant of petroleum toxicity to aquatic organisms? Aquatic Toxicology, v. 46, n. 3-4, p. 253-268, 1999.

BRASIL. Ministério do Meio Ambiente. Conselho Nacional do Meio Ambiente. Resolução n 397 de 3 de abril de 2008. Brasília, DF, 2008.

COELHO, A. et al. Treatment of petroleum refinery sourwater by advanced oxidation processes. Journal of Hazardous Materials, v. 137, n. 1, p.178184, 2006.

DACERA, D.D.M; BABEL, S. Removal of heavy metals from contaminated sewage sludge using Aspergillus niger fermented raw liquid from pineapple wastes. Bioresource Technology, v. 99, n. 6, p. 1682-1689, 2008.

DEMRC, S.; ERDOGAN, B.; OZCMDER, R. Wastewater treatment at the petroleum refinery, Kirikkale, Turkey using some coagulants and Turkish clays as coagulant aids. Water research, v. 32, n. 11, p. 3495-3499, 1998

DUPUIT, E. et al. Decision support methodology using rule-based reasoning coupled to non-parametric measurement for industrial wastewater network management. Environmental Modelling \& Software, v. 22, n. 8, p. 1153-1163, 2007
DRIESSEN, W.; YSPEERT, P. Anaerobic treatment of low, medium and high strength effluent in the agro-industry. Water Science and Technology, v. 40, n. 8 , p. 221-228, 1999.

EGGEN, T.; MAJCHERCZYK, A. Removal of polycyclic aromatic hydrocarbons $(\mathrm{PAH})$ in contaminated soil by white rot fungus Pleurotus ostreatus. International Biodeterioration and Biodegradation. v. 41, n. 2 p. 111-117, 1998

ESPOSITO, E.; AZEVEDO, J.L. Fungos: uma introdução à biologia, bioquímica e biotecnologia. Caxias do Sul: Educs, 2004.

FÉLIX, J.P.L. et al. Remoção de DQO e fenóis totais presentes em efluentes de indústria petrolífera utilizando reatores de leito fixo e fluxo contínuo inoculados com Aspergillus niger AN400. In: KATO, M.T Gestão e tratamento de resíduos líquidos gerados na cadeia produtiva do petróleo: $1^{a}$ coletânea de trabalhos técnicos. Recife: Editora Universitária da UFPE, 2006. p. 183-198.

FICA-PIRAS, P. Estudos sobre nitrificação de efluentes de refinaria em biorreatores trifásicos. Tese (Doutorado em Engenharia Quimica) UFRJ, Rio de Janeiro, 2000.

FREITAS NETO, M.A. et al. Remoção de compostos nitrogenados de águas residuárias de refinarias de petróleo através de reatores biológicos com fungos. Revista Tecnologia, Fortaleza, v. 28, n. 1, p.8596, jun. 2007.

GARCIA, I.G. et al. Removal of phenol compounds from olive Mill wastewater using Phanerochaete chrysosporium, Aspergillus niger Aspergillus terreus and Geotrichum candidum. Process Biochemistry, v. 35 , p. $751-758,2000$

GODJEVARGOVA, T. et al. Biodegradation of toxic organic components from industrial phenol production waste water by free and immobilized Trichosporon cutaneum R57. Process Biochemistry, v. 38, n. 6, p. 915 920, 2003

GRIFFIN, D.H. Fungal physiology. 2. ed. New York: Wiley-Liss, 1994

$\mathrm{HAQ}$, I.U. et al. Optimization of nitrogen for enhanced citric acid productivity by a 2-deoxy D-glucose resistant culture of Aspergillus niger NGd-280. Bioresource Technology, v. 96, n. 5, p. 645-648, 2005.

HERNÁNDEZ, M.S. et al. Amylase production by Aspergillus niger in submerged cultivation on two wastes from food industries. Journal of Food Engineering, v. 73, n. 1, p. 93-100, 2006. 
HWANG, S.C. etal. Removal of multiple nitrogenous wastes by Aspergillus niger in a continuous fixed-slab reactor. Bioresource Technology, v. 93, n. 2, p. 131-138, 2004.

JOHNSON, C.H.; PAGE, M.W.; BLAHA, L. Full scale moving bed biofilm reactor results from refinery and slaughter house treatment facilities. Water Science and Technology, v. 41, n. 4-5, p.401-407, 2000.

JOU, C.G.; HUANG, G. A pilot study for oil refinery wastewater treatment using a fixed-film bioreactor. Advances in Environmental Research, v. 7 , p. 463-469, 2002.

KATO, M.T. et al. The anaerobic treatment of low strength wastewater in UASB and EGSB reactors. Water Science and Technology, v. 36, n. 6-7, p. 375-382, 1997.

KOTSOU, M. et al. Integrated aerobic biological treatment and chemical oxidation with Fenton's reagent for the processing of green table olive wastewater. Process Biochemistry, v. 39, n. 11, p.16531660, 2004.

KYRIACOU, A. et al. Combined bioremediation and advanced oxidation of green table olive processing wastewater. Process Biochemistry, v. 40, n. 3-4, p. 1401-1408, 2005

LEITÃO, R.C. et al. The effects of hydraulic and organic shock loads on the robustness of upflow anaerobic sludge blanket reactors treating sewage. Water Science and Technology, v. 54, n. 2, p. 49-55, 2006.

MARIANO, J.B. Impactos ambientais do refino de petróleo. Tese (Mestrado em Ciências em Planejamento Energético) - UFRJ, Rio de Janeiro, 2001.

MIRANDA, M.P. et al. Color elimination from molasses wastewater by Aspergillus niger. Bioresource Technology, v. 57, n. 3, p. 229-235, 1996.

MISHRA, B.K.; LATA, A.A. Optimization of a biological process for treating potato chips industry wastewater using a mixed culture of Aspergillus foetidus and Aspergillus niger. Bioresource Technology, v. 94, n. 1, p. 9-12, 2004.

MORDOCCO, A.; KUEK, C.; JENKINS, R. Continuous degradation of phenol at low concentration using immobilized Pseudomonas putida. Enzyme and Microbial Technology, v. 25, n. 6, p.530-536, 1999.

OLIVEIRA, E.C. et al. Degradação de fenóis por leveduras presentes em águas residuárias de refinarias de petróleo. In: Gestão e tratamento de resíduos líquidos gerados na cadeia produtiva do petróleo: $1^{\text {a }}$ coletânea de trabalhos técnicos. Recife: Editora Universitária da UFPE, 2006. p. 133-148.

RAO, J.R.; VIRARAGHAVAN, T. Biosorption of phenol from an aqueous solution by Aspergillus niger biomass. Bioresource Technology, v. 85, n. 2, p. 165-171, 2002.

RODRIGUES, K.A. et al. Biodegradação de fenol por Aspergillus niger em água residuária sintética. In: $23^{\circ}$ CONGRESSO BRASILEIRO DE ENGENHARIA SANITÁRIA E AMBIENTAL, CBESA, Campo Grande: Associação Brasileira de Engenharia Sanitária e Ambiental - ABES, 2005. CD-ROM.
ROUKAS, T.; HARVEY, L. The effect of $\mathrm{pH}$ on production of citric and gluconic acid from beet molasses using continuous culture. Biotechnology Letters, v. 10, n. 4, p. 289-294, 1988.

SAMPAIO, G.M.M.S. et al. Emprego de reatores biológicos com fungos para remoção de parathion. In: XI SIMPÓSIO LUSO-BRASILEIRO DE ENGENHARIA SANITÁRIA E AMBIENTAL - SILUBESA, Natal: Associação Brasileira de Engenharia Sanitária e Ambiental - ABES, 2004A. CD-ROM.

Pós-tratamento de efluente de um reator UASB através de um reator biológico com fungos. Revista Engenharia Sanitária e Ambiental, v. 9, n.1, p.73-81, jan./mar, 2004B.

SANTAELLA, S.T. et al. Remoção de fenol em reatores biológicos com fungos (RBF) utilizando meio suporte e água residuária sintética. In: $23^{\circ}$ CONGRESSO BRASILEIRO DEENGENHARIASANITÁRIAEAMBIENTAL, CBESA, Campo Grande: Associação Brasileira de Engenharia Sanitária e Ambiental - ABES, 2005. CD-ROM.

Emprego de fungos para tratamento biológico dos efluentes da indústria de beneficiamento da castanha de caju. In: VI SIMPÓsIO ÍTALO-BRASILEIRO DE ENGENHARIA SANITÁRIA E AMBIENTAL, Vitória: Associação Brasileira de Engenharia Sanitária e Ambiental ABES, 2002. CD-ROM

SANTOS, E.M.A. et al. Influência do tempo de detenção hidráulica em um sistema UASB seguido de um reator biológico com fungos para tratar efluentes de indústria de castanha de caju. Revista Engenharia Sanitária e Ambiental, v. 11, n. 1, p. 39-45, jan./mar. 2006.

SANTOS, V.L.; LINARDI, V.R. Biodegradation of phenol by a filamentous fungi isolated from industrial effluents - identification and degradation potencial. Process Biochemistry, v. 39, p. 1001-1006, 2004.

SOUSA, O.L. et al. Tratamento biológico de águas residuárias de indústria petroquímica através de reatores aeróbios inoculados com Candida sp. In: Gestão e tratamento de resíduos líquidos gerados na cadeia produtiva do petróleo: $1^{\text {a }}$ coletânea de trabalhos técnicos. Recife: Editora Universitária da UFPE, 2006. p. 149-165.

STEPNOWSKI, P. et al. Enhanced photo-degradation of contaminants in petroleum refinery wastewater. Water Research, v. 36, n. 9, p. 2167-2172, 2002.

STRINGFELLOW, W.T.; ALVAREZ-COHEN, L. Evaluating the relationship between the sorption of PAHs to bacterial biomass and biodegradation. Water Research, v. 33, n. 11, p. 2535-2544, 1999.

TAKAYA, N. Dissimilatory nitrate reduction metabolisms and their control in fungi. Journal of Bioscience and Bioengineering, v. 94, n. 6, p. 506-510, 2002

TAKAYA, N. et al. Cytochrome P450nor, a novel class of mitochondrial cytochrome P450 involved in nitrate respiration in the fungus fusarium oxysporum. Archives of Biochemistry and Biophysics, v. 372, n. 2, p. 340346,1999

TRIOLA, M.F. Introdução à estatística. $7^{\text {a }}$ ed. Rio de Janeiro: ETC, 1998.

VASSILEV, N. et al. Olive mill waste water treatment by immobilized cells of Aspergillus niger and its enrichment with soluble phosphate. Process Biochemistry, v. 32, n. 7, p. 617-620, 1997. 
WAGNER, M.; NICELL, J.A. Peroxidase-catalyzed removal of phenols from a petroleum refinery wastewater. Water Science and Technology, $v$. 43, n. 2, p. 253-260, 2001

YAVUZ, Y.; KOPARAL, A.S. Electrochemical oxidation of phenol in a parallel plate reactor using ruthenium mixed metal oxide electrode. Journal of Hazardous Materials, v. 136, n. 2, p. 296-302, 2006.
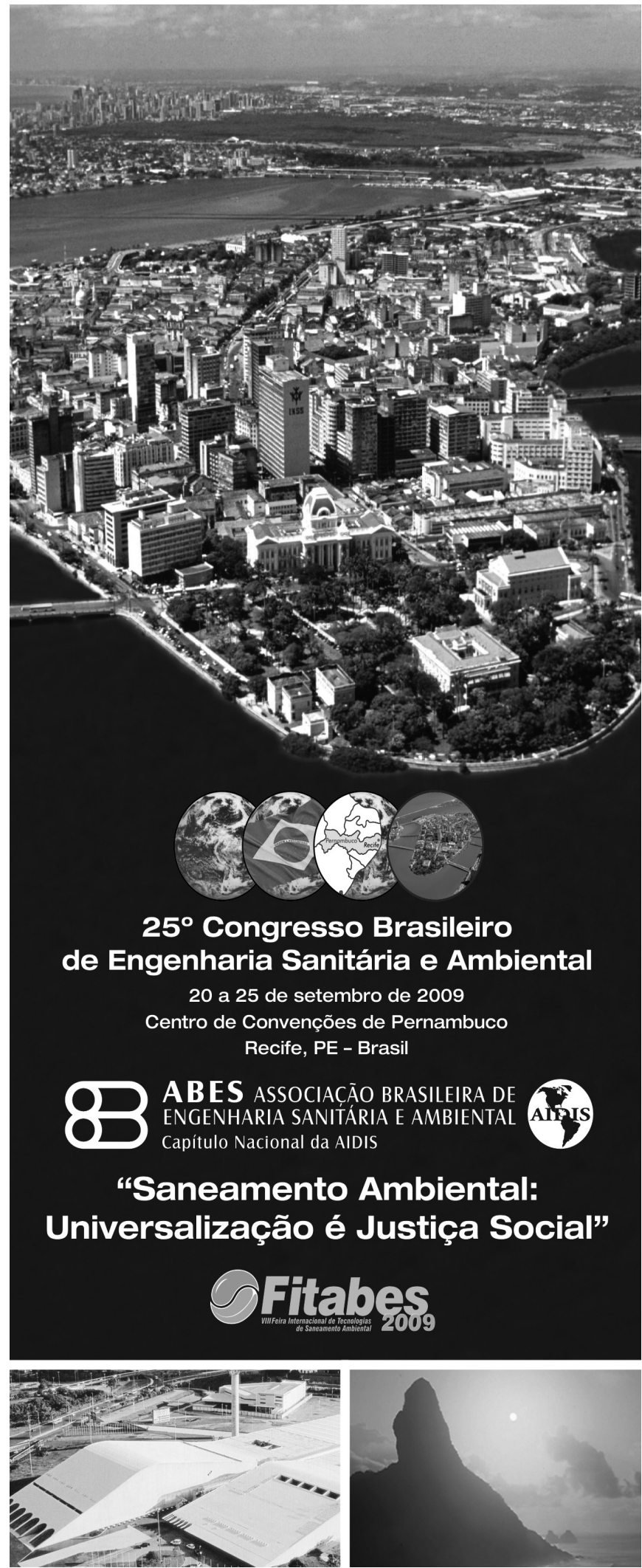